\title{
Cinema e Teatralidade: Deslocamento mítico e ressignificação espaço-temporal na minissérie $A$ Pedra do Reino
}

Yuri de Andrade Magalhães ${ }^{1}$

Jerônimo Vieira de Lima Silva²

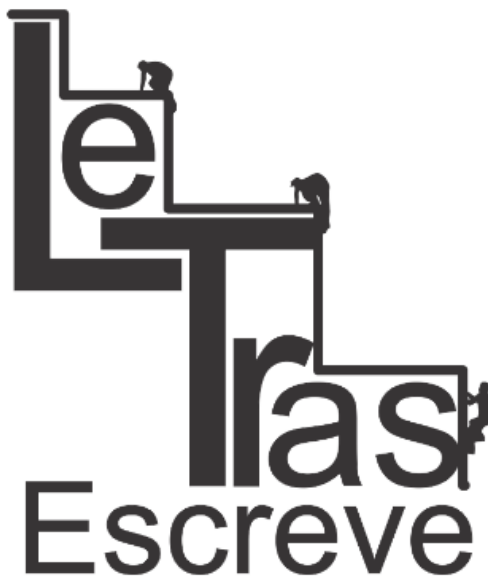

(ISSN 2238-8060)
Resumo: $O$ presente artigo tem como objetivo analisar a utilização teatral do espaço-tempo na minissérie A Pedra do Reino, transmitida pela Rede Globo de Televisão em 2007, sob direção de Luiz Fernando Carvalho. Em sua adaptação do Romance d'A Pedra do Reino e o Principe do Sangue do Vai-e-Volta, de Ariano Suassuna, podemos observar que o diretor da minissérie se utiliza frequentemente de elementos simbólicos para a recriação da espacialidade nordestina, deixando-a transparecer sua teatralidade por meio de soluções cênicas a fim de representar a transição de tempo, uma vez que a estrutura textual in media res da obra original de Ariano Suassuna sugere uma fragmentação do tempo. A utilização desses elementos se dá através de uma intencional apropriação de diferentes matrizes estéticas, a saber: a nordestina, a árabe e a europeia medieval. Essa apropriação espacial também se estende para o campo da narrativa, pois podemos perceber citações indiretas a tragédias e epopeias clássicas que, mescladas com a lenda do rei Dom Sebastião e o ideal de um reino encantado da poesia, viabilizam esse deslocamento mítico de várias vertentes para o sertão do nordeste brasileiro.

Palavras-chaves: Literatura, Deslocamento Mítico, Ressignificação, Pedra do Reino, Cinema.

Abstract: This article aims to analyze the theatrical use of space-time in the miniseries A Pedra do Reino, transmitted by Globo Television Network in 2007, directed by Luiz Fernando Carvalho. In his adaptation of the Romance da Pedra do Reino e o Principe do Sangue do Vai-e-Volta, we can notice that the director of the miniseries often uses symbolic elements for rebuilding the brazilian northeastern spatiality, transpiring its theatrical connotation by using solutions to represent the transition time, once that the textual structure in media res of the original Ariano Suassuna's work suggest a fragmentation of time. The use of these elements is made by an intentional appropriation of different aesthetic matrices, for example: the brazilian northeast region, arabic and medieval Europe influence. This spatial appropriation also extends to the its narrative, as we can see indirect quotes from the classical tragedies and epics that merged with the legend of the Portuguese king Dom Sebastião and the imaginary existence

\footnotetext{
${ }^{1}$ Professor do Curso de Teatro da Universidade Regional do Cariri-URCA. E-mail: magalhaes.teatro@gmail.com

${ }^{2}$ Professor do Curso de Teatro da Universidade Regional do Cariri-URCA. E-mail: jeravieira@yahoo.com.br
}

https://periodicos.unifap.br/index.php/letras

Macapá, v. 6, n. I, Io semestre, 2016. 


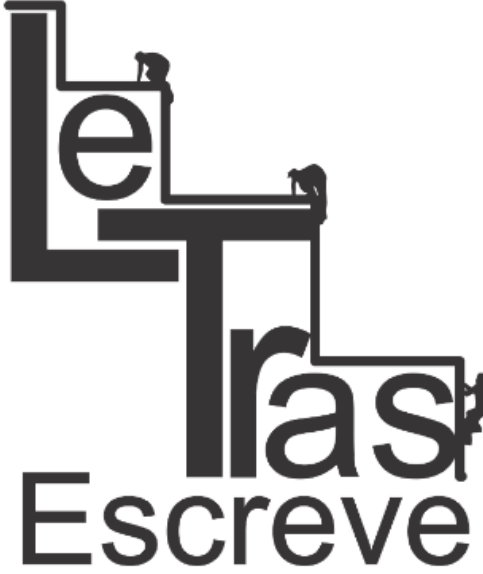

(ISSN 2238-8060) of a enchanted realm of poetry, enable this mythical displacement of several strands to the northeastern Brazil.

Keywords: Literature, Mythical Displacement, Reframing, Pedra do Reino, Cinema.

No ano de 2007, a Rede Globo de Televisão exibiu a seus telespectadores, em comemoração aos 80 anos de idade do escritor Ariano Suassuna, a minissérie intitulada $A$ Pedra do Reino, sob a direção de Luiz Fernando Carvalho, inspirada na obra do autor intitulada Romance d' A Pedra do Reino e o Príncipe do Sangue do Vai-e-Volta. Ao ler a obra e assistir à minissérie, podemos perceber que tanto o autor quanto o diretor optaram por uma abordagem aparentemente não linear que siga "adequadamente" as unidades aristotélicas de tempo, espaço e lugar.

Ariano Suassuna, em sua obra, opta por uma estrutura in media res onde o protagonista, Pedro Dinis Quaderna, situa o leitor acerca dos acontecimentos que o levaram à situação em que se encontra - preso em uma cadeia. Tanto a leitura da obra quanto à apreciação da minissérie exige um leitor / espectador "avisado", uma vez que o trabalho de Ariano Suassuna, na obra em si, e Luiz Fernando Carvalho, na adaptação para a TV, parece não se destinar a um público que possua poucas referências no que concerne à cultura nordestina popular, que dialoga diretamente com a cultura europeia medieval que cá se enraizou, bem como ainda possuindo ecos notáveis da cultura clássica da Antiguidade.

Conforme aponta Lima (2010), buscando aprofundar-se no melhor da tradição popular nordestina e na estrutura de um texto popular/erudito que possui formas estéticas variadas, pertencentes ao mesmo tempo ao litoral e ao sertão - as quais são ligadas às nossas origens ibéricas -, em 1958, Suassuna começou a escrever o romance d'A Pedra do Reino e o Príncipe do Sangue Vai- e-Volta, sendo este adaptado, anos depois para o cinema, como disse antes. O autor paraibano conseguiu enriquecer sua obra de uma matériaprima sublime - crença popular, superstições, religiosidade e moralidade popular -, unindo o espontâneo ao elaborado; o popular

https://periodicos.unifap.br/index.php/letras Macapá, v. 6, n. I, Io semestre, 2016. 


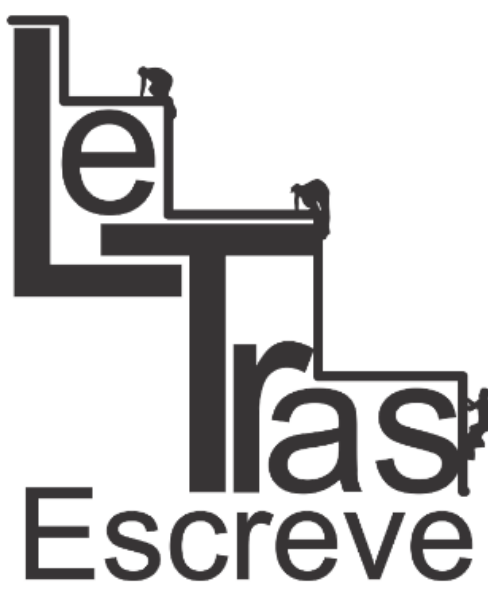

(ISSN 2238-8060) ao erudito; a linguagem comum ao estilo do verso; o regional ao universal. Ressaltamos também o encontro e a influência do autor com outras formas populares de cultura como os espetáculos de mamulengo, o Bumba-meu-boi e o circo, além, claro, do cinematográfico. (LIMA, 2010)

Sendo assim, em sua produção literária, é possível perceber, como relata Lima (2010), modelos formais dramáticos da alta literatura ocidental como também influência do teatro religioso medieval, sobretudo ibérico, na qual se acrescentam traços elementares do barroco, associando-se com formas estéticas da dramaturgia profana vigentes na época de transição do período medieval para o renascimento, como a Comédia Dell'Arte e de outras estéticas que muito contribuíram para a essência Literária de Suassuna, sendo por este motivo, uma obra de denso valor estético e cultural; de difícil entendimento.

Luiz Fernando Carvalho em sua minissérie apela para uma "suspensão da descrença" no espectador brasileiro que já se acomodou a uma estrutura narrativa na televisão onde tudo deve se esclarecer de maneira "plausível" e tudo deve supostamente chegar a algum lugar, ou algum resultado. $O$ diretor coloca em evidência o seu potencial criativo, demarcando o lugar do diretor como também um "re-criador" da obra literária, muitas vezes acrescentando aspectos que o autor possivelmente não havia pensado. Sob o seu olhar criativo, Carvalho situa a vila de Taperoá em uma cidade cenográfica que possui uma perspectiva quadrangular, o espaço representativo de Taperoá se encontra cercado entre quatro paredes de casas, e dois imensos portões se abrem e se fecham para a entrada de personagens.

O tempo da memória e o tempo presente se entrecortam tanto na obra quanto na minissérie, essa aparente ausência de definição entre o que é passado e presente, entre o que aconteceu antes ou depois, torna-se ainda mais evidente quando Carvalho coloca Pedro Dinis Quaderna, ora participando ativamente das suas lembranças

https://periodicos.unifap.br/index.php/letras Macapá, v. 6, n. I, Io semestre, 2016. 


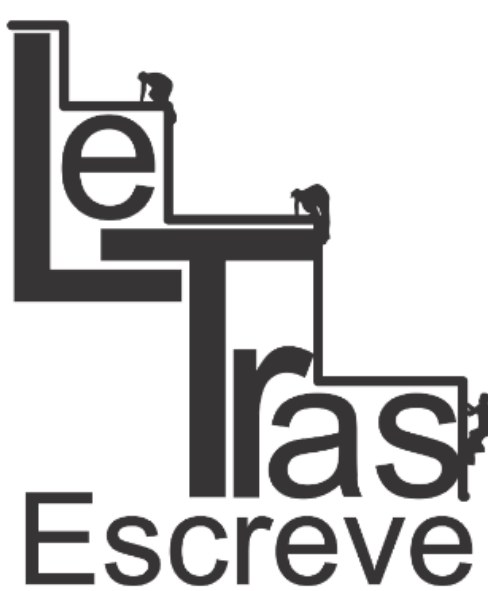

(ISSN 2238-8060)

(como geralmente ocorre quando nos lembramos de algo), ora presenciando fatos da sua lembrança em terceira pessoa, assistindo aos acontecimentos como se houvesse sido transportado para o tempo da memória.

Logo no inicio da minissérie podemos ressaltar um aspecto da teatralidade da obra, ou melhor, da metateatralidade. A minissérie inicia com todos os personagens dançando em uma grande roda de ciranda, onde Pedro Dinis Quaderna se encontra dançando ao centro, notavelmente envelhecido, corcunda, com maquiagens pesadas, e um figurino que nos remete simultaneamente a Miguel de Cervantes e a seu personagem mais célebre, Dom Quixote. Essa semelhança entre Pedro Dinis Quaderna e Dom Quixote, em determinados trechos da minissérie, parece bastante pertinente, uma vez que Quaderna é um personagem notoriamente "quixotesco". Assim como Dom Quixote, grande parte da obra de Suassuna e da minissérie de Carvalho é preenchida com os devaneios que oscila entre a loucura e a lucidez de Quaderna.

De acordo com informações contidas na obra Almanaque Armorial, organizada pelo pesquisador Carlos Newton Júnior (2008), Ariano Suassuna teve influências de nomes conceituados da história do teatro clássico e da literatura mundial como Boccaccio, Cervantes, Stendhal, Plauto, Homero, Virgílio, Dostoievski, Calderón de La Barca, Gil Vicente, Lope de Vega, Molière, Shakespeare, Federico Garcia Lorca etc, além de influências que melhor representaram o Romanceiro Popular Nordestino entre as quais podemos citar José Laurenio de Melo, Leandro Gomes de Barros, Leonardo Mota, Francisco Brennand, Maritain e Bérgson, Chico da Silva; e influências de teóricos, pesquisadores e literários que escreveram a história da cultura e da literatura brasileira como Gilberto Freyre, Euclides da Cunha, Guimarães Rosa, Augusto dos Anjos, José Lins do Rego. Dessa forma, ressalta-se aqui, como dissemos antes, a influência do "quixotesco" na obra do autor, dentre outras. (LIMA, 2010) 
Continuando nossa análise, podemos observar que a roda de ciranda com todos os personagens é um aspecto potencialmente meta-teatral, pois na ocasião o diretor parece querer mostrar ao espectador que tudo aquilo é "apenas teatro", buscando fazer com que o espectador entenda que estamos todos em uma "comunhão", como geralmente se busca no teatro; uma comunhão entre ator e espectador, apelando todavia para a "suspensão da descrença", conforme mencionei anteriormente neste artigo.

Assim como as tragédias e as epopeias clássicas, a obra de Ariano Suassuna é permeada por momentos líricos, épicos e dramáticos. Suassuna introduz em sua obra um elemento que foi de fundamental importância para a preservação e sobrevivência das epopeias de Homero, o rapsodo. O rapsodo na Grécia é um grande responsável pela tradição oral que manteve viva por várias gerações os cantos da llíada e da Odisseia. Os rapsodos eram poetas cantadores que cantavam trechos das epopeias em locais públicos, em festejos religiosos, e até mesmo em frente às residências dos gregos. Desta forma, o rapsodo se insere como um elemento lírico e épico na cultura clássica.

Possivelmente imbuído dessa influência do rapsodo, Ariano Suassuna, seguido por Luiz Fernando Carvalho, apresenta inicialmente uma apresentação inicial de Pedro Dinis Quaderna, conforme podemos observar:

Há três anos passados, na Véspera de Pentecostes, dia $1^{\circ}$ de Julho de 1935, pela estrada que nos liga à Vila de Estaca-Zero, vinha se aproximando de Taperoá uma cavalgada que iria mudar o destino de muitas das pessoas mais poderosas do lugar, incluindo entre estas o modesto Cronista-Fidalgo, Rapsodo-Acadêmico e Poeta-Escrivão que lhes fala neste momento. (SUASSUNA, 2007, p.35)

Na minissérie A Pedra do Reino, podemos observar que o diretor optou por fazer um deslocamento temporal no que concerne ao cenário. Na minissérie, no momento em Pedro Dinis Quaderna se dirige ao público explicando-os sobre a trama que está por vir, ele 


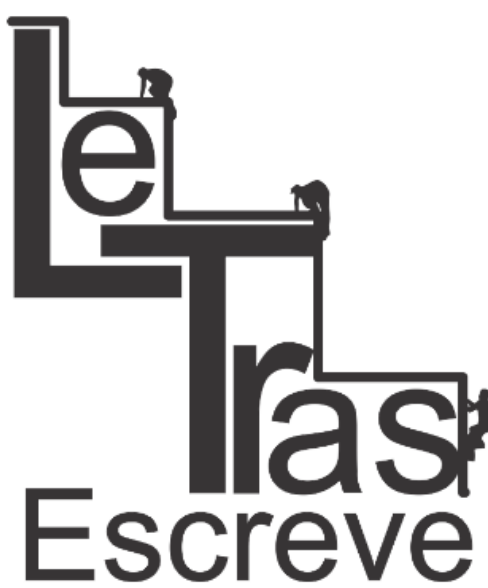

(ISSN 2238-8060) pronuncia tais palavras de cima um "carro-palco", esse carro-palco é completamente feito de madeira e possui uma estrutura que segue o formato de uma casa capaz de girar 360 graus sob o próprio eixo.

Ao utilizar o "carro-palco", Luiz Fernando Carvalho nos transporta diretamente para o teatro religioso existente no decorrer da Idade Média. O carro-palco foi um elemento frequentemente presente nos autos sacramentais portugueses e espanhóis e nos mistérios na Inglaterra e França, bem como nas farsas e soties que ocorriam, com maior frequência, nos intervalos dos mistérios. Deste modo nós podemos entender o carro-palco de Quaderna como um elemento de ressignificação espaço-temporal.

No que concerne ao "deslocamento mítico" na Pedra do Reino de Luiz Fernando Carvalho, podemos deduzir, a principio, que a própria estrutura da cidade cenográfica de Taperoá é uma possível menção à cidade de Tróia, famosa por suas imponentes e intransponíveis muralhas. Na homérica Tróia existem dois imensos portões que é por onde se dá a entrada e a saída principal da cidade; esses mesmos portões assumem função de entrada da vila de Taperoá.

O deslocamento mítico também permeia as páginas do romance de Ariano Suassuna bem como as cenas da minissérie de Luiz Fernando Carvalho. A começar pela enigmática morte do influente ancião Pedro Sebastião Garcia-Barretto, tio e padrinho do protagonista Pedro Dinis Quaderna. Pedro Sebastião GarciaBarretto é sempre descrito como um rei generoso e bondoso, Quaderna sempre faz questão de enfatizar as qualidades de seu padrinho e o desejo de algum dia vingar seu assassinato.

Podemos deduzir que Ariano Suassuna se inspirou no rei Príamo, de Tróia, para compor seu personagem. Sabemos que Príamo é considerado um modelo de rei bondoso e generoso. A influência mítica na Pedra do Reino também se estende à tragédia grega, a exemplo da vingança da morte do pai na trilogia de Ésquilo, Oréstia, e a temática da disputa pelo trono entre os dois irmãos

https://periodicos.unifap.br/index.php/letras Macapá, v. 6, n. I, Io semestre, 2016. 
filhos de Édipo em Os Sete Contra Tebas do mesmo tragediógrafo. Em entrevista realizada em sua residência na cidade de Recife/PE em Agosto de 2013, Ariano Suassuna admite:

Tem um parentesco muito... inclusive, a Orestíada é um livro que me toca muito, e Ésquilo é um dramaturgo que me toca muito, Ésquilo e Sófocles, mas Ésquilo sobretudo por causa de Orestes por causa daquilo que lhe disse... Então você tem Orestes... e você tem Hamlet e Horácio, filhos como Orestes de um rei assassinado. Não é? E você tem Ariano Suassuna (Risos), filho de um rei assassinado. (MAGALHAES, 2013, p.128)

Além da influência da Orestíada de Ésquilo, o autor também admite na mesma entrevista que a disputa entre Arésio e Sinésio pela herança de Pedro Sebastião Garcia-Barretto é uma herança

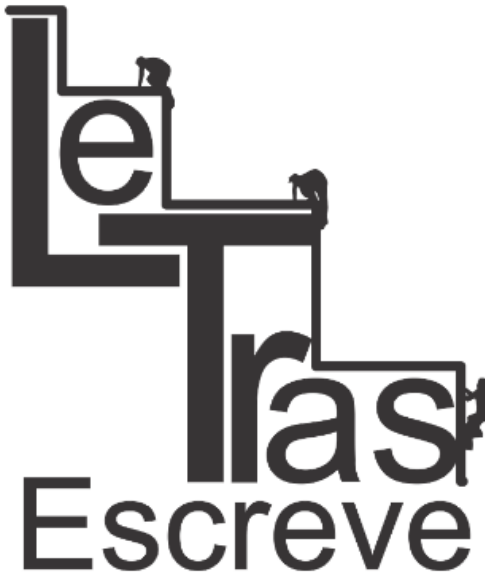

(ISSN 2238-8060) literária da disputa de Etéocles e Polinices pelo trono de Tebas em Os Sete Contra Tebas. Podemos observar que o diretor Luiz Fernando Carvalho coloca notória ênfase na disputa entre os dois irmãos. Um elemento repleto de possíveis significações é o figurino utilizado em cena pelos personagens Arésio e Sinésio, o diretor optou por vestir os personagens com uma indumentária atípica da realidade sertaneja. Sinésio veste uma armadura prateada e Arésio, frequentemente nu da cintura para cima, utiliza uma capa vermelha. Podemos entender nessa indumentária uma possível menção aos beligerantes heróis das epopeias.

Outro fato existente na minissérie, porém não na obra de Suassuna, é o momento em que Pedro Sebastião Garcia-Barretto pede que Pedro Dinis Quaderna acompanhe seu filho caçula, Sinésio, à Natal, onde supostamente Sinésio ficaria protegido dos rivais políticos de seu velho pai, na casa de Swendson. Podemos também deduzir que essa atitude de Pedro Sebastião GarciaBarretto em esconder o filho em outra cidade está ancorada na postura tomada pelo rei de Tróia, Príamo, ao enviar seu filho mais novo, Polidoro, para a Trácia, onde lá estaria oculto dos inimigos de Tróia, os gregos, protegido pelo rei Polimestor. O rei da Trácia, 


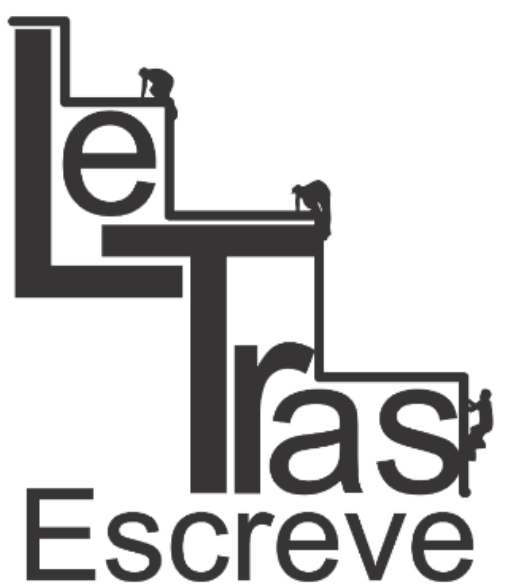

(ISSN 2238-8060) contudo, ao saber da queda de Tróia, mata Polidoro, e na tragédia de Eurípedes intitulada Hécuba, Polimestor é alvo da vingança de Hécuba pela morte de seu filho caçula.

Nas últimas partes da minissérie e da obra, Pedro Dinis Quaderna está enfrentando um inquérito. Lembremos que o romance começa com a narração de Quaderna feita a partir de sua cela na cadeia, todo o romance se constrói no objetivo de esclarecer ao leitor como o protagonista chegou àquela situação. Duas situações sustentam o eixo narrativo do romance de Suassuna; a morte de Pedro Sebastião Garcia-Barretto e achegada de Sinésio à vila de Taperoá após cinco anos de desaparecimento, o que ocasiona a disputa política entre os dois irmãos Arésio e Sinésio.

Conforme já falamos anteriormente o assassinato de Pedro Sebastião Garcia-Barretto está, segundo admite o próprio autor, ancorada (além dos fatos pessoais do próprio autor) na tradição mítica da Antiguidade, no assassinato de Agamênon por Clitemnestra e Egisto na trilogia Orestíada de Ésquilo e a temática da rivalidade entre os dois irmãos está ancorada na rivalidade entre Etéocles e Polinices em Os Sete Contra Tebas, também de Ésquilo. Contudo, o desaparecimento o exílio de Sinésio, também presente em muitos heróis trágicos da Antiguidade como Édipo e Orestes, é uma influência direta do mito de Dom Sebastião, rei de Portugal, que desapareceu na batalha de Alcácer-Quibir contra os mouros na África.

Podemos observar que na obra de Ariano Suassuna, Sinésio é descrito por Quaderna como o grande esperado pela população de Taperoá, que crê que será libertada da miséria e da opressão quando Sinésio a ela retornar. Esse caráter messiânico de Sinésio, diretamente inspirado em Dom Sebastião, é potencializado por Luiz Fernando Carvalho que, designou para o papel um ator que possui feições semelhantes às que o mundo atribui a Jesus Cristo, cabelos compridos e olhos claros. Em dissertação escrita sobre o Romance d'A Pedra do Reino, podemos observar:

https://periodicos.unifap.br/index.php/letras Macapá, v. 6, n. I, Io semestre, 2016. 


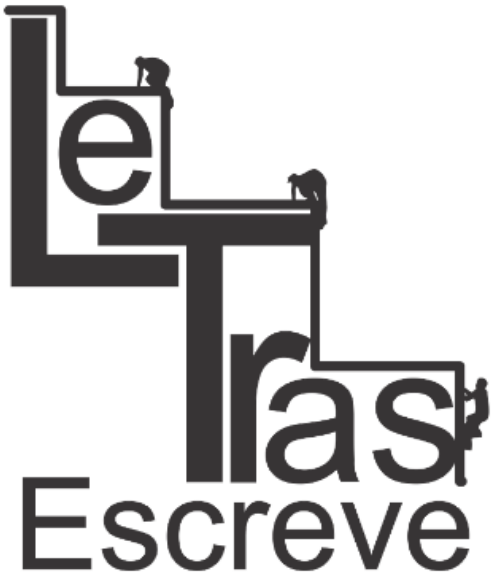

(ISSN 2238-8060)

Pelas razões políticas mencionadas anteriormente, o rei $D$. Sebastião era esperado pelo povo português antes mesmo de seu nascimento, passando a ser também conhecido como "O Desejado". No Romance d'A Pedra do Reino, a espera pelo retorno de Sinésio faz com que este seja chamado, por Pedro Dinis Quaderna, como "O Alumioso". Versões conflituosas também servem para reforçar o aspecto mítico tanto em $D$. Sebastião quanto em Sinésio. Em relação ao desaparecimento de D. Sebastião dizia-se que ele havia sido morto, e seu corpo recolhido pelos árabes, outras versões apontam que ele simplesmente não foi encontrado após a batalha de AlcácerQuibir. No romance de Ariano Suassuna há pessoas que crêem que Sinésio foi seqüestrado, outros crêem que ele fugiu, e há também a versão do irmão mais velho (Arésio) que diz ter visto o cadáver de Sinésio. (MAGALHÃES, 2013, p. 96)

A postura altiva e silenciosa de Sinésio montado em seu cavalo branco utilizando uma armadura, como mencionado anteriormente, também nos remete a duas figuras que habitam o imaginário do povo cristão: São Jorge e o Apóstolo Santiago. Luiz Fernando Carvalho coloca grande ênfase na temática do "retorno do Rapaz-do-Cavalo-Branco", lembremo-nos que o apóstolo Santiago é também conhecido como Rapaz-do-Cavalo-Branco e, segundo relatos, foi visto combatendo os mouros junto aos espanhóis, passando a ser conhecido como Matamoros. ${ }^{3} \mathrm{Na}$ obra de Ariano Suassuna, bem como na minissérie, Sinésio é visto como um personagem mítico e também descrito como "Rapaz-do-CavaloBranco".

Nas cenas referentes ao inquérito na minissérie, podemos observar que é onde há, possivelmente, maior trabalho de ressignificação do espaço de representação e maior metateatralidade. Enquanto na obra de Ariano Suassuna podemos observar uma narração feita a um juiz-corregedor, Luiz Fernando Carvalho traz para a cena, além do depoimento de Quaderna, personagens que surgem literalmente naquele recinto à medida que Quaderna os evocava. Contudo, ao mesmo tempo em que os personagens pareciam estar literalmente ali, sendo vistos tanto por

\footnotetext{
${ }^{3}$ Mata-mouros.
}

https://periodicos.unifap.br/index.php/letras

Macapá, v. 6, n. I, Io semestre, 2016. 


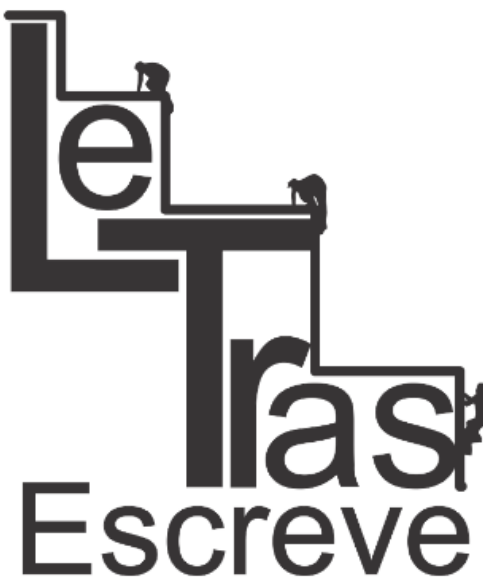

(ISSN 2238-8060)
Quaderna quanto pelo corregedor, cabe ao espectador compreender que aqueles personagens não se encontravam ali, todos eles compunham a imaginação de Quaderna, e todos estavam ali sentados assistindo ao inquérito de Quaderna como se estivessem diante de um monólogo, denotando assim um aspecto puramente metateatral, o teatro dentro do teatro.

O passado e o presente se encontram ali na cena do inquérito. Tanto para o leitor da obra quanto para o espectador da minissérie, Ariano Suassuna parece não ter o compromisso com as unidades aristotélicas, contudo podemos constatar que respeita a unidade de tempo, conforme podemos observar na entrevista contida na dissertação de Yuri de Andrade Magalhães sobre o romance onde lhe é perguntado se a ausência de uma linearidade na obra é uma contraposição intencional à unidade aristotélica, o autor responde: "Não, olhe, eu sou um admirador das unidades aristotélicas... Não sei se você se lembra, mas a Pedra do Reino, em si, ela dura um dia". (MAGALHAES, 2013, p.128)

\section{REFERÊNCIAS BIBLIOGRÁFICAS}

BEIGUI, Alex. Dramaturgia por Outras Vias: A Apropriação Como Matriz Estética do Teatro Contemporâneo - Do Texto Literário à Encenação. São Paulo/SP: Universidade de São Paulo, 2006. (Tese de Doutorado)

BERTHOLD, Margot. História Mundial do Teatro. $3^{\mathrm{a}}$ ed. São Paulo: Perspectiva, 2006.

RODRIGUES, Wellington. A Representação do Diabo no Teatro Vicentino e seus Aspectos Residuais no Teatro Quinhentista do Padre José de Anchieta e no Contemporâneo de Ariano Suassuna. Fortaleza/CE: UFC, 2010 (Dissertação de Mestrado)

SUASSUNA, Ariano. Romance d'A Pedra do Reino e o Principe do Sangue do Vai-e-Volta. 9a Ed. Rio de Janeiro: José Olympio, 2007.

https://periodicos.unifap.br/index.php/letras Macapá, v. 6, n. I, Io semestre, 2016. 
- Almanaque Armorial. Seleção, organização e prefácio

Carlos Newton Júnior. Rio de Janeiro: José Olympio, 2008.

MAGALHAES, Yuri de Andrade. A Travessia do Trágico no

Romance d'A Pedra do Reino de Ariano Suassuna. Natal/RN:

UFRN, 2013. (Dissertação de Mestrado)

Recebido em 18/03/2016. Aprovado em 02/05/2016.

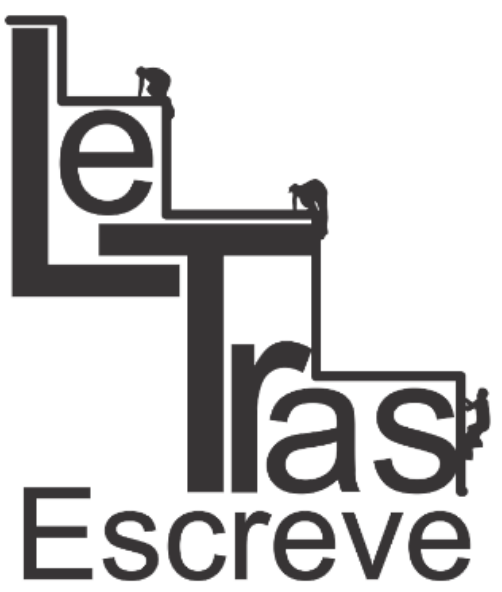

(ISSN 2238-8060) 